\title{
Developmental controls are re-expressed during induction of neurogenesis in the neocortex of young adult mice
}

\author{
U. Shivraj Sohur ${ }^{1,2,3 \neq}$, Paola Arlotta ${ }^{1,2,3 t \neq}$ and Jeffrey D. Macklis ${ }^{1,2,3 *}$ \\ ${ }^{1}$ Department of Stem Cell and Regenerative Biology and Harvard Stem Cell Institute, Harvard University, Cambridge, MA, USA \\ 2 Program in Neuroscience, Departments of Neurology and Neurosurgery, MGH-HMS Center for Nervous System Repair, Harvard Medical School, Boston, MA, USA \\ ${ }^{3}$ Nayef Al-Rodhan Laboratories, Massachusetts General Hospital, Boston, MA, USA
}

\section{Edited by: \\ Jack M. Parent, University of \\ Michigan, USA}

\section{Reviewed by:}

Francis G. Szele, Oxford University, UK

Steven W. Levison, UMDNJ New Jersey Medical School, USA

Joshua Corbin, Children's National

Medical Center, USA

\section{*Correspondence:}

Jeffrey D. Macklis, Department of Stem Cell and Regenerative Biology, Harvard University, 7 Divinity Avenue, Bauer Laboratory 103, Cambridge,

MA 02138, USA.

e-mail: jeffrey_macklis@hms.

harvard.edu

\section{${ }^{\dagger}$ Present address:}

Paola Arlotta, Department of Stem Cell and Regenerative Biology,

Harvard University, 7 Divinity Avenue, Sherman-Fairchild Building 358C,

Cambridge, MA 02138, USA.

${ }^{*} U$. Shivraj Sohur and Paola Arlotta have contributed equally to this work.
Whether induction of low-level neurogenesis in normally non-neurogenic regions of the adult brain mimics aspects of developmental neurogenesis is currently unknown. Previously, we and others identified that biophysically induced, neuron subtype-specific apoptosis in mouse neocortex results in induction of neurogenesis of limited numbers of subtype-appropriate projection neurons with axonal projections to either thalamus or spinal cord, depending on the neuron subtype activated to undergo targeted apoptosis. Here, we test the hypothesis that developmental genes from embryonic corticogenesis are re-activated, and that some of these genes might underlie induction of low-level adult neocortical neurogenesis. We directly investigated this hypothesis via microarray analysis of microdissected regions of young adult mouse neocortex undergoing biophysically activated targeted apoptosis of neocortical callosal projection neurons. We compared the microarray results identifying differentially expressed genes with public databases of embryonic developmental genes. We find that, following activation of subtype-specific neuronal apoptosis, three distinct sets of normal developmental genes are selectively re-expressed in neocortical regions of induced neurogenesis in young adult mice: (1) genes expressed by subsets of progenitors and immature neurons in the developing ventricular and/or subventricular zones; (2) genes normally expressed by developmental radial glial progenitors; and (3) genes involved in synaptogenesis. Together with previous results, the data indicate that at least some developmental molecular controls over embryonic neurogenesis can be re-activated in the setting of induction of neurogenesis in the young adult neocortex, and suggest that some of these activate and initiate adult neuronal differentiation from endogenous progenitor populations. Understanding molecular mechanisms contributing to induced adult neurogenesis might enable directed CNS repair.

Keywords: induced adult neocortical neurogenesis, developmental molecular controls, cortex

\section{INTRODUCTION}

There is increasing evidence that elements of the molecular controls over developmental neurogenesis during brain formation also control homologous aspects of constitutive neurogenesis in the hippocampal dentate gyrus and olfactory bulb (Magavi et al., 2005; Sohur et al., 2006; Steele et al., 2006; Alvarez-Buylla et al., 2008; Suh et al., 2009; Ma et al., 2010; Kempermann, 2011), but whether the same is true of induction of neurogenesis in normally non-neurogenic regions is unknown. Substantial progress has recently been made in understanding molecular controls over corticogenesis and neocortical neuron subtype-specific neurogenesis during development (Molyneaux et al., 2007; Leone et al., 2008; Shoemaker and Arlotta, 2010; Fame et al., 2011; MacDonald et al., 2012). It is increasingly being identified that there is remarkable heterogeneity and diversity of partially fate-restricted progenitors in the developing CNS (Chambers et al., 2001; Hack et al., 2005; Kohwi et al., 2005; Molyneaux et al., 2005; Wu et al., 2005; Gal et al., 2006; Costa et al., 2007; Merkle et al., 2007; Mizutani et al., 2007; Lai et al., 2008; Lledo et al., 2008; Azim et al., 2009a) and that there are lineage- and subtype-specific molecular controls over the specification, differentiation, and ultimate function of broad classes and distinct subtypes of cortical projection neurons (Arlotta et al., 2005; Chen et al., 2005; Molyneaux et al., 2005, 2007; Ozdinler and Macklis, 2006; Sohur et al., 2006; Alcamo et al., 2008; Britanova et al., 2008; Joshi et al., 2008; Lai et al., 2008; Azim et al., 2009a,b; Bedogni et al., 2010; Tomassy et al., 2010; Han et al., 2011; McKenna et al., 2011). Collectively, these studies are beginning to identify the complex molecular controls over developmental neurogenesis within the mammalian neocortex.

In contrast, almost nothing is understood about molecular controls that might be mechanistically involved in activation and/or regulation of induced neurogenesis in the adult mammalian neocortex (Wang et al., 1998; Magavi et al., 2000; Chen et al., 2004; Brill et al., 2009). Based on the similarities and conserved mechanisms identified by many groups between developmental and adult neurogenesis in the hippocampal dentate gyrus and olfactory bulb, we hypothesized that there might potentially 
be recapitulation of at least some molecular controls over normal embryonic neocortical neurogenesis during induced adult neurogenesis. We directly investigated this hypothesis via microarray analysis of microdissected regions of young adult mouse neocortex undergoing biophysically activated targeted apoptosis of neocortical callosal projection neurons (CPN; Macklis, 1993; Sheen and Macklis, 1995; Hernit-Grant and Macklis, 1996; Wang et al., 1998; Leavitt et al., 1999; Magavi et al., 2000; Scharff et al., 2000; Fricker-Gates et al., 2002; Chen et al., 2004). We targeted $\mathrm{CPN}$ as the most abundant projection neuron class maximally enabling optimal gene expression analysis. These conditions were previously identified to result in induction of low-level neurogenesis in the neocortex of young adult mice $(\sim 100$ newborn neurons $/ \mathrm{mm}^{3}, 2$ weeks after induction) by our lab and others (Magavi et al., 2000; Chen et al., 2004; Brill et al., 2009) and in the zebra finch forebrain song system (Scharff et al., 2000). Other groups have reported complementary results in other normally non-neurogenic regions - e.g., the hippocampus outside of the dentate gyrus (Nakatomi et al., 2002) and striatum (Arvidsson et al., 2002; Parent et al., 2002) - following controlled hypoxia to produce selective vulnerability and apoptosis in targeted neuron subtypes. We compared the microarray results identifying differentially expressed genes with public databases of embryonic developmental genes. Our experiments enable direct investigation of potential re-expression of molecular controls from embryonic neurogenesis in the setting of induction of adult neocortical neurogenesis.

\section{MATERIALS AND METHODS \\ ANIMALS AND EXPERIMENTAL DESIGN}

All animal studies were approved by the Massachusetts General Hospital Institutional Animal Care and Use Committee, and performed in accordance with institutional and federal guidelines. We focused on the sensorimotor cortex (in the area $\sim+1 \mathrm{~mm}$ anterior to $-1.5 \mathrm{~mm}$ posterior from bregma - exact start location depended on blood vessel anatomy), and we biophysically targeted $\mathrm{CPN}$, cortical pyramidal neurons that connect the two cerebral hemispheres, by unilateral injection of chlorin $\mathrm{e}_{6}$-conjugated fluorescent latex nanospheres between postnatal days 1 and 3 inbred C57/B16 mice of either sex (P1-P3; day of birth P0) based on established protocols (e.g., Magavi et al., 2000). After 8 weeks, subtype-specific targeted apoptosis of contralateral CPN was initiated in the experimental mice by near-infrared laser activation, as previously described (Figures 1A,B). Six-hundred seventy nanometers laser energy was applied to the contralateral sensorimotor cortex through an $\sim 2-\mathrm{mm}$ diameter craniotomy directly contralateral to the initial nanosphere injection site, to induce synchronous apoptotic degeneration of nanosphere-containing CPN (Macklis, 1993; Sheen and Macklis, 1995; Magavi et al., 2000; Chen et al., 2004). Control mice were injected under the same surgical conditions at the same neonatal age, except with targeting nanospheres that were not conjugated with chlorin $\mathrm{e}_{6}$; allowed to survive for the same period of time until 8 weeks of age; then treated with the same procedural, anesthetic, and surgical conditions for a photo-exposure step (including use of the same fiberoptic, timing of procedure, and laser light exposure).
PREPARATION OF TISSUE AND RNA EXTRACTION AND HYBRIDIZATION

Based on previous experiments where we had determined when maximum induced transcriptional activity occurs in situ after initiation of biophysical degradation (e.g., Wang et al., 1998), 8 days after chlorin $\mathrm{e}_{6}$-mediated $\mathrm{CPN}$ apoptosis, mice were deeply anesthetized, the craniotomy site was exposed, and a $2-\mathrm{mm} \times 2$ $\mathrm{mm} \times 0.5-\mathrm{mm}$ sample (enriching for layers II/III, and thus excluding the VZ/subventricular zones, SVZ) of cortex was microdissected from the center of each of the regions of targeted apoptosis (Figure 1C). Subsequently, mice were euthanized by additional anesthesia. For each of three biological replicates, microdissected samples from eight experimental neocortical hemispheres were collected and pooled, and compared with matched samples pooled from eight control mice (total of 24 experimental and 24 control mice). Each sample was placed in RNAlater (Ambion, Inc.) immediately after microdissection, and stored at $-80^{\circ} \mathrm{C}$.

RNA was extracted using the StrataPrep Total RNA Mini Kit (Stratagene, La Jolla, CA, USA), and RNA quality was assessed using a bioanalyzer (Agilent Technologies, Palo Alto, CA, USA). RNA ( $10 \mu \mathrm{g}$ of RNA per biological replicate) was hybridized to Affymetrix GeneChip Murine Genome U74 Version 2 [MGU74Av2; contains probes for more than 12,400 transcripts, coding for 7,000 mouse genes and 5,000 expressed sequence tags (ESTs)] according to the manufacturer's protocol (Affymetrix; Santa Clara, CA, USA) and as previously described (Figure 1D; Arlotta et al., 2005).

\section{TRANSCRIPTOME ANALYSIS OF REGIONS UNDERGOING INDUCED NEUROGENESIS IN THE YOUNG ADULT MOUSE}

We combined two statistical approaches, and integrated the results to optimize rigor, and raise confidence in gene expression changes that were identified.

\section{Statistical analysis of microarrays}

To identify genes that are differentially expressed in regions undergoing induced adult neurogenesis with very high confidence, we used two different approaches to analyze the Affymetrix data. In the first, we applied the robust multi-array average (RMA) function within Bioconductor (Irizarry et al., 2003), and the "Error Model" method within Rosetta Resolver (version 5.0, Rosetta Biosoftware, Seattle, WA, USA). Statistical significance of gene expression differences between control and experimental tissue expression was determined using statistical analysis of microarrays (SAM; Tusher et al., 2001). We used a $P$-value of $<0.05$ as a filter for differentially expressed genes.

\section{Multivariate analysis of variance (linear modeling; MANOVA)}

To even more stringently analyze the results, we subjected the six .CEL files to GC-content-based robust multi-array average (GCRMA) normalization (Irizarry et al., 2003). Expression levels were $\log$ (base 2) transformed. The number of genes was reduced from 12,488 to 4,349 by requiring a "presence call" for at least $50 \%$ in a group of samples classified by experimental treatment. All calculations were done using $\mathrm{R}$ and Bioconductor computational tools (Gentleman, 2005). To identify differentially expressed genes between groups of samples, we applied the multivariate analysis of variance approach (also known as linear modeling; MANOVA) 
to fit gene expression levels (log2 transformed) according to the defined groups of samples and Bayesian posterior error analysis (Smyth, 2004). Genes that exhibited a $P$-value $\leq 0.05$ and fold change greater than 1.5 were considered significantly differentially expressed.

\section{COMPARING THE INDUCED ADULT NEUROGENESIS DATASET WITH DEVELOPING NEOCORTEX TRANSCRIPTOME DATA}

Gene expression in neural progenitors from developing mouse cortex has been profiled by other groups (Pinto et al., 2008; Sanosaka et al., 2008). The deposited .CEL files of the Affymetrix raw data from these publications were accessed at the National Center for Biotechnology Information's Gene Expression Omnibus (GEO) $)^{1}$.

\section{Genes differentially expressed between early-and mid-neocortical neurogenesis}

The Nakashima laboratory previously compared expression profiling in neural stem/progenitor cell cultures ("NSC") of the telencephalon from mouse embryonic day (E) 11.5 (early neocortical neurogenesis) and E14.5 (mid-neocortical neurogenesis; Sanosaka et al., 2008; GEO Accession Number: GSE10796).

\section{Genes differentially expressed in radial glia subtypes}

Gotz and colleagues used a mouse line that expresses green fluorescent protein (GFP) driven by a human glial fibrillary acidic protein ( $h G F A P)$ promoter to profile gene expression by radial glial subtypes (Pinto et al., 2008; GEO Accession Number: GSE8034). At E14.5, during the mid-neurogenic phase in the neocortex, essentially all GFAP positive cells are radial glia. Two subtypes of radial glia were isolated in the cortical prominin positive (CD133+;

\footnotetext{
${ }^{1}$ http://www.ncbi.nlm.nih.gov/gds
}

ventricular neural cell precursors) population by FACS: those that expressed high levels of GFAP (i.e., CD133 + GFAP ${ }^{\text {hi }}$ ), and those that expressed low levels of GFAP (CD133+ GFAPlow $)$. Because these experiments investigated gene expression in highlevel GFAP-expressing cells, we added Gfap to this dataset as a "differentially" expressed gene.

A gene list for each individual dataset was generated using MANOVA/linear modeling analysis approach.

\section{IN SITU HYBRIDIZATION IMAGES}

From the analysis above, we searched established databases of gene expression to identify representative patterns of expression for target genes, primarily using the Eurexpress/Genepaint consortium ${ }^{2}$ (Visel et al., 2004). Sagittal E14.5 mouse in situ hybridization images are shown in Figure 2: Cry2 (T50260); Litaf (T31645); Myo10 (T36658); Nelf(T5943).

\section{RESULTS}

We identified genes differentially expressed in regions of induced neurogenesis in the neocortex of young adult mice. Specifically, we find that regions of young adult neocortex undergoing induction of neurogenesis differentially express genes that are active during normal development in neural precursors and radial glia, and during synaptogenesis. These data suggest that some normal neocortical developmental molecular controls are re-activated during induced young adult neocortical neurogenesis.

We identified differentially expressed genes by comparative transcriptional profiling and analysis between microdissected regions undergoing induction of young adult cortical neurogenesis and matched control regions. The two analysis and statistical approaches employed both indicated that genes previously identified as specifically expressed during normal forebrain development

${ }^{2}$ http://www.eurexpress.org/ee/intro.html

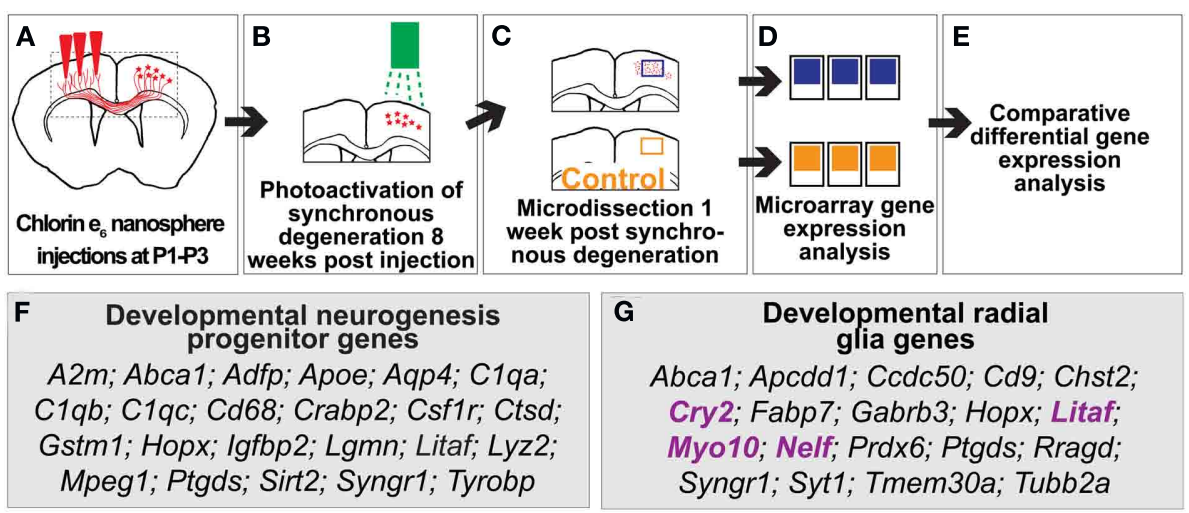

FIGURE 1 | Genes involved in developmental neocortical neurogenesis are differentially expressed in regions of induced young adult neocortical neurogenesis. (A-E) Approach to identify differentially expressed genes in regions of induced young adult neurogenesis. (A) Coronal representation of a mouse brain, indicating site of injection (red arrows) of chlorin $\mathrm{e}_{6}$-conjugated nanospheres into mice at postnatal day 1-3 (P1-P3; day of birth P0) to label callosal projection neurons (CPN; red somas in right cortex). Dashed box represents the area of focus in (B,C). (B) Photoactivation of chlorin $\mathrm{e}_{6}$-conjugated nanospheres within the lysosomes of CPN to induce apoptotic
CPN degeneration at 8 weeks of age. (C,D) Microdissection and microarray comparative differential gene expression analysis of regions of induced young adult neurogenesis and control tissue. (E) 107 genes were identified as differentially expressed in regions of induced young adult neurogenesis. (F) Genes differentially expressed in regions of induced young adult neurogenesis in common with genes expressed in mid-neurogenesis in neural progenitor cell culture. (G) Genes expressed in regions of induced young adult neurogenesis in common with genes expressed by developmental radial glia. The genes indicated in purple are those shown in Figure 2. 

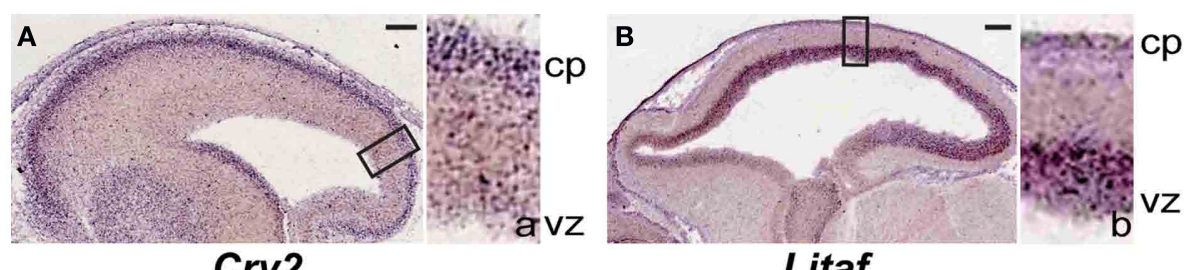

Cry2

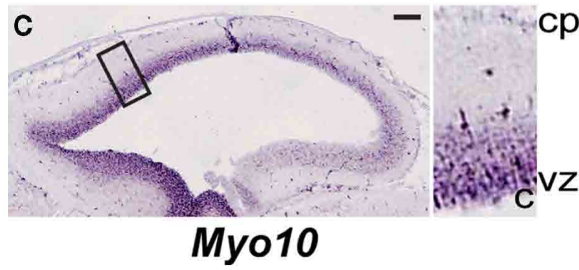

FIGURE 2 | Genes differentially re-expressed in regions of induced young adult neurogenesis previously not specifically identified to be expressed during neocortical development. (A-D) Sagittal sections of in situ hybridization of embryonic day (E) 14.5 mouse obtained from the publicly available Genepaint/Eurexpress consortium (data presented with permission). Insets to the right in each panel are higher magnification views of the boxed

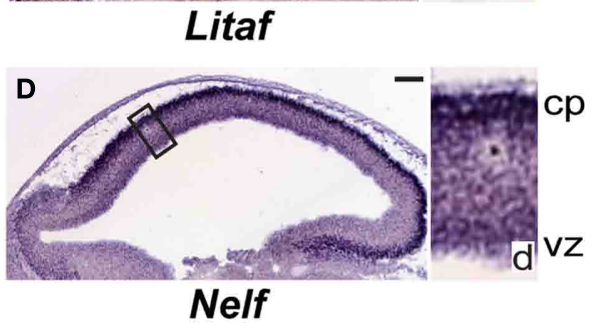

areas in the main images; these are denoted by the corresponding lower-case letter. (A) Cry2 is predominantly expressed in the developing cortical plate. Litaf (B) and Myo10 (C) are expressed strongly in the ventricular zone. (D) Nelf is highly expressed in the developing cortical plate, and also diffusely throughout the thickness of the cortex. cp, cortical plate; vz, ventricular zone. Scale bars, $100 \mu \mathrm{m}$. See text for details. are re-activated during induced young adult neocortical neurogenesis. These include genes previously identified as expressed by developmental neural progenitors (Sanosaka et al., 2008) and developmental radial glia (Pinto et al., 2008). We then accessed publicly available in situ hybridization expression databases to identify which of these genes are regionally expressed in the germinal zone (VZ, SVZ) of the developing neocortex.

\section{DIFFERENTIALLY EXPRESSED GENES IN REGIONS UNDERGOING INDUCED YOUNG ADULT NEOCORTICAL NEUROGENESIS}

The SAM method identified 83 genes differentially expressed in regions of induced young adult neocortical neurogenesis, while the MANOVA method identified 55 differentially expressed genes; 31 genes were common to both analyses. Together, the results of both transcriptome analyses identified 107 genes as differentially expressed (either over- or under-expressed) in regions of induced young adult neocortical neurogenesis (Figure 1E; Table A1 in Appendix). These genes likely have relatively high degrees of differential expression that can be detected even from heterogeneous tissue. This very focused set of differentially expressed genes reinforces the specificity of gene activation in this system, and suggests that many are likely critical in induced young adult neurogenesis.

\section{GENES DIFFERENTIALLY EXPRESSED IN REGIONS OF INDUCED YOUNG ADULT NEOCORTICAL NEUROGENESIS IN COMMON WITH MURINE DEVELOPING NEOCORTICAL TRANSCRIPTOME DATABASES \\ Radial glial genes are expressed in regions of induced young adult neurogenesis}

We first analyzed the previously published datasets for CD133 + GFAP ${ }^{\text {hi }}$ vs. CD133 + GFAPlow murine radial glia at E14.5 (Pinto et al., 2008) and identified over 1,200 genes differentially expressed between these populations (data not shown). Nineteen genes were common between those differentially expressed in regions of induced young adult neocortical neurogenesis and this radial glia dataset (Figure 1G); this represents
Table 1 | Genes differentially expressed in regions of induced young adult neurogenesis that are associated with and expressed by developmental radial glia.

\begin{tabular}{llll}
\hline Gene & Description & Fold change & $\boldsymbol{P}$-value \\
\hline Fabp7 & Lipid transporter & 1.53 & 0.02 \\
Gfap & Cytoskeletal protein & 3.93 & $2.98 \times 10^{-3}$
\end{tabular}

$\sim 20 \%$ of the differentially expressed genes in regions of induced adult neocortical neurogenesis. Two well-known radial glia genes stand out: Fabp7 (also known as Blbp; Rousselot et al., 1997; Hartfuss et al., 2001; Zimmerman and Veerkamp, 2002; Anthony et al., 2004; Arai et al., 2005) and Gfap (Leavitt et al., 1999; Shapiro et al., 2005; Emsley and Macklis, 2006; Chojnacki et al., 2009; Table 1). These results reinforce that radial glial-like progenitors likely contribute to induced neocortical neurogenesis.

\section{Developmental synaptogenic genes are expressed in regions of induced young adult neurogenesis}

Sanosaka et al. (2008) compared neural progenitor cell cultures generated from mouse telencephalon at E11.5 vs. E14.5. Our analysis of their raw Affymetrix dataset revealed over 1,300 genes as differentially expressed between these two types of cultures (data not shown). Twenty-three of the differentially expressed genes in regions of induced young adult neocortical neurogenesis are common to this developmental progenitor dataset (Figure 1F): $\sim 23 \%$ of our dataset of differentially expressed genes in regions of induced young adult neocortical neurogenesis. Of these, it is interesting to note that several genes are known to be involved in synaptogenesis and/or maintenance of synapses, e.g., Abcal (Hirsch-Reinshagen et al., 2004; Kim et al., 2008; Karasinska et al., 2009); Apoe (Masliah et al., 1995; Hirsch-Reinshagen et al., 2004; Wahrle et al., 2004); C1qa, C1qb, and C1qc (Stevens et al., 
2007); Ctsd (Mariani et al., 2006; Partanen et al., 2008); Syngr1 (Belizaire et al., 2004; Verma et al., 2004), and Tyrobp (a.k.a. Dap12/Karap; Roumier et al., 2004; Nataf et al., 2005; Table 2). These results strongly suggest that induced young adult neurogenesis involves active plastic changes of synapse formation, pruning, and/or reorganization.

\section{IDENTIFICATION OF GENES DIFFERENTIALLY EXPRESSED IN REGIONS OF INDUCED YOUNG ADULT NEUROGENESIS THAT HAVE NOT PREVIOUSLY BEEN STUDIED IN NEOCORTICAL DEVELOPMENT, BUT ARE EXPRESSED IN DEVELOPING CORTICAL VENTRICULAR ZONE AND CORTICAL PLATE}

From our dataset of 107 genes, we identified genes (e.g., Cry2, Litaf, Myo10, and Nelf; Table 3) previously not studied in the neocortex, that are interestingly expressed regionally in the cortex at E14.5 (Figures 2A-D). Litaf and Myo10 are expressed in the ventricular zone, and Cry 2 and Nelf are expressed in the cortical plate. These results suggest homology of potential molecular mechanisms between developmental neocortical neurogenesis and induced young adult neocortical neurogenesis.

\section{DISCUSSION}

In this report, we provide evidence at the level of microarray analysis that at least some developmental molecular controls over developmental neurogenesis are re-activated in the setting of induction of neurogenesis in the young adult neocortex. Although mouse strain differences in adult neurogenesis are present in details of timing and magnitude of response (Schauwecker, 2006), the results in our report are generalizable. Specifically, we find at the

Table 2 | Genes differentially expressed in regions of induced young adult neurogenesis known to be involved in synaptic development, function, and plasticity.

\begin{tabular}{llll}
\hline Gene & Significance & Fold change & $P$-value \\
\hline Abca1 & Lipid transporter & 3.40 & $1.04 \times 10^{-3}$ \\
Apoe & Lipid transporter & 1.20 & $4.00 \times 10^{-4}$ \\
C1qa & Cell-cell signaling & 2.77 & 0.01 \\
C1qb & Cell-cell signaling & 2.48 & $1.50 \times 10^{-3}$ \\
C1qc & Cell-cell signaling & 2.23 & 0.01 \\
Ctsd & Protease & 1.62 & 0.03 \\
Syngr1 & Presynaptic vesicle integral & 2.71 & $3.30 \times 10^{-4}$ \\
& membrane protein & & \\
Tyrobp & Transmembrane signal trans- & 2.39 & $4.84 \times 10^{-4}$ \\
& ducing peptide & & \\
& & &
\end{tabular}

Table 3 | Genes differentially expressed in regions of induced young adult neurogenesis not previously studied in the neocortex, but expressed in the developmental neocortical ventricular zone, subventricular zone, and cortical plate.

\begin{tabular}{llll}
\hline Gene & Significance & Fold change & $\boldsymbol{P}$-value \\
\hline Cry2 & Lipid metabolism & 2.24 & $3.27 \times 10^{-3}$ \\
Litaf & Transcription factor & 1.57 & 0.01 \\
Myo10 & Cytoskeletal protein & 1.96 & $3.11 \times 10^{-3}$ \\
Nelf & Axon guidance & 3.85 & 0.03
\end{tabular}

microarray level that genes normally expressed in the developing ventricular and/or SVZ, radial glial progenitors, and genes involved in synaptogenesis are selectively re-expressed at the microarray level in neocortical regions of induced young adult neurogenesis. In addition, we identify differential expression of several genes not previously identified as expressed in the developing neocortex.

\section{NINETEEN GENES CONNECTED TO RADIAL GLIA AND RADIAL GLIAL PROGENITOR FUNCTION ARE DIFFERENTIALLY EXPRESSED BY MICROARRAY ANALYSIS IN REGIONS OF INDUCED YOUNG ADULT NEOCORTICAL NEUROGENESIS}

Radial glia are critical components of the developing cerebral cortex, both as cellular scaffolds along which newly born projection/pyramidal neurons migrate to their final positions, and as neural progenitors during later stages of cortical development (Hartfuss et al., 2001; Noctor et al., 2001; Gotz et al., 2002) and in other regions of the telencephalon such as the ganglionic eminences (Anthony et al., 2004; Chojnacki et al., 2009). Our analysis identified the re-expression of multiple genes associated and functionally connected with radial glial/progenitor and neuron migration roles in cortical development.

For example, fatty acid binding protein 7 (Fabp7)/brain lipid binding protein (Blbp; Zimmerman and Veerkamp, 2002) and glial acidic fibrillary protein ( $G f a p$ ) were both identified as differentially expressed in regions activated to undergo induced neurogenesis. Fabp7/Blbp is expressed during development exclusively by radial glia and astrocytes (Anthony et al., 2004). It has been proposed that Fabp7/Blbp has a role in adult neurogenesis, since it is heavily expressed in the adult canary brain, which exhibits high levels of neurogenesis (Rousselot et al., 1997). Prior work from our laboratory (Hernit-Grant and Macklis, 1996) identified that stellate astroglia partially de-differentiate into $\sim 150 \mu \mathrm{m}$ long radial glia in the setting of targeted apoptosis and migration of immature neurons, potentially a cellular population re-expressing Fabp7/Blbp. Expression by activated radial glial-like progenitors is another possibility. GFAP is a major intermediate filament protein expressed by radial glia and astroglia; it is used as a marker for astroglia during development and when activated. It is also expressed in the adult SVZ where GFAP-expressing "SVZ astrocytes" are multipotent neural progenitors (Doetsch et al., 1999; Alvarez-Buylla et al., 2001; Seri et al., 2001; Chojnacki et al., 2009). Upregulation of Gfap might represent activation or proliferation of radial glia or radial glia-like neural progenitors in regions of induced adult neurogenesis. Our previous work (e.g., Macklis, 1993) indicates that Gfap expression is unlikely to be due to gliosis in this biophysically activated targeted apoptosis leading to induction of neurogenesis. Also of note, the U74Av2 Affymetrix microarray we utilized does not contain the probe sets for Glast, another important marker for radial glia; in this microarray analysis, it would have been interesting to investigate its expression in the experimental tissue.

\section{INCREASED EXPRESSION BY MICROARRAY ANALYSIS OF SYNAPSE-RELATED GENES IN REGIONS OF INDUCED YOUNG ADULT NEUROGENESIS \\ Our analysis also identified the increased expression of mul- tiple genes associated with formation and maintenance of synapses during initial cortical development. Development and}


stabilization of new synapses is predicted in regions of induced adult neurogenesis, and is consistent with much prior work in the field (Magavi et al., 2000, 2005; Scharff et al., 2000; FrickerGates et al., 2002). As examples, we highlight three differentially expressed genes/gene groups involved in synapse development and maintenance.

Barres and colleagues identified that $C 1 q$, in addition to its known role in the immune complement cascade, is also important in eliminating and shaping synapses (Stevens et al., 2007). All of the three components of $C 1 q(C 1 q a, C 1 q b, C 1 q c)$ are differentially over-expressed in regions of induced adult neurogenesis (Figure 1F).

Synaptotagmin 1 (Syt1) is also differentially over-expressed in regions of induced young adult neurogenesis. It is a member of the synaptotagmin family of integral membrane proteins that are located on synaptic vesicles, and is important for neurotransmitter release. These data are consistent with the generation of new synapses onto and by newly incorporated neurons.

Tyrobp (Karap/Dap-12), a gene related to the CD3 $\zeta$ signaling polypeptide associated with the T-cell receptor, is also differentially expressed in regions of induced young adult neurogenesis. Tyrobp is critical to synaptic function through its action in microglia, in which it is expressed (Roumier et al., 2004). Mice deficient in Tyrobp have decreased postsynaptic AMPA receptor GluR2 expression, with substantial effects on synaptic plasticity (Roumier et al., 2004; Nataf et al., 2005). Tyrobp differential expression is consistent with new synapse formation, establishment, and plasticity in the setting of induced adult neocortical neurogenesis.

Taken together, the differential over-expression of several synapse-related genes reinforces the interpretation that synaptogenesis is ongoing in the setting of induced adult neurogenesis. Both formation of synapses onto newborn neurons, and formation of new synapses by those neurons, might jointly account for the increase in synaptogenic genes following induction of adult neurogenesis.

\section{GENES DIFFERENTIALLY RE-EXPRESSED BY MICROARRAY ANALYSIS IN REGIONS OF INDUCED YOUNG ADULT NEUROGENESIS PREVIOUSLY NOT SPECIFICALLY IDENTIFIED TO BE EXPRESSED DURING NEOCORTICAL DEVELOPMENT}

Other genes identified as differentially over-expressed in regions activated to undergo induced neocortical neurogenesis were previously not recognized to be expressed in the developing cortex. We searched gene expression databases and the primary literature regarding these genes in other systems or CNS regions, revealing their expression in progenitors and developing neurons of the cortical plate. Their regional and temporal expression during corticogenesis, combined with their differential over-expression in the setting of induced young adult neocortical neurogenesis, suggest the re-expression of these genes as functional in cortical development and both developmental and adult neurogenesis. Four examples of such genes are Cry2, Litaf, Myo10, and Nelf. Identification of these genes as both highly expressed during initial corticogenesis in developing VZ/SVZ and cortical plate, and during induction of adult neocortical neurogenesis, suggests functional linkage between developmental and induced cortical neurogenesis.

\section{Cryptochrome 2 (Cry2)}

Cry2 has been described as a circadian clock gene (Ishida, 2007), but we identify it from the publicly available Genepaint/Eurexpress consortium to be expressed strongly in the cortical plate at E14.5 (Figure 2A). This suggests potential function for Cry2 during developmental corticogenesis, and during induced cortical neurogenesis.

\section{Lipopolysaccharide-induced TNF factor (Litaf)}

Litaf is expressed strongly in the neocortical germinal zone at E14.5 (Figure 2B), again suggesting function in developmental and young adult cortical neurogenesis, in addition to previously identified function in other systems. Litaf mutations result in the peripheral neuropathy syndrome Charcot-MarieTooth (CMT) 1c, which accounts for between 1 and $2 \%$ of all CMT1 (Street et al., 2003; Bird, 2010). The biological function of lipopolysaccharide-induced TNF factor (LITAF) is not well understood. It was originally cloned as a transcription factor modulating the tumor necrosis factor- $\alpha(T N F \alpha)$ gene (Polyak et al., 1997; Myokai et al., 1999), but it has also been found to encode a lysosomal protein (Moriwaki et al., 2001). Litaf has not been investigated regarding potential function in cortical development. It would be of interest to determine whether Litaf has a critical functional role during developmental corticogenesis, and, if so, whether it functions through the TNF signaling pathway, as a lysosomal protein, or by another mechanism.

\section{Myosin 10 (Myo10)}

Myo10 was also identified as differentially over-expressed in the setting of induction of young adult neocortical neurogenesis. Myo10 is a member of the myosin family of molecular motors. We identified from Genepaint/Eurexpress that it exhibits strong expression in the neocortical germinal zone (Figure 2C). Recently, a shorter version of Myolo that does not contain the stereotypical "head" that allows these proteins to act as molecular motors was shown to be expressed by CNS neurons during development (Sousa et al., 2006). It would be of interest to investigate the specific isoform(s) expressed in the developmental germinal zone to gain insight into potential function during developmental neurogenesis.

\section{Nasal embryonic LHRH factor (Nelf)}

We also identified Nelf as differentially over-expressed in the setting of young adult neocortical neurogenesis, and from Genepaint/Eurexpress as being strongly expressed in the cortical plate (Figure 2D). Nelf is known as a guidance molecule previously reported to be responsible for axonal outgrowth of olfactory neurons (McTavish et al., 2007). It would be of interest to investigate potential function(s) during developmental and induced adult neurogenesis.

\section{MOLECULAR CONTROLS AND MECHANISMS EXPRESSED DURING DEVELOPMENTAL CORTICOGENESIS ARE RE-EXPRESSED BY MICROARRAY ANALYSIS IN REGIONS OF INDUCED YOUNG ADULT NEUROGENESIS}

Taken together, these experiments and analysis demonstrate that multiple molecular controls and likely functional mechanisms 
active during normal developmental neurogenesis are reexpressed during induced neurogenesis in the neocortex. Genes implicated in developmental neocortical neurogenesis, synaptogenesis, and radial glial progenitor and migrational function are re-expressed with induction of young adult neocortical neurogenesis.

Finally, it is important to note that non-mutually exclusive possibilities exist that together might contribute to the induction of neurogenesis of neurons ultimately residing in neocortex in experiments parallel to those reported here. Progenitors (quite possibly distinct subsets of the much broader set of SVZ progenitors) appear to be activated and mobilized from the young adult SVZ (as reported in Magavi et al., 2000). Additionally, populations of intra-parenchymal progenitors that have been identified by multiple groups might contribute through more local activation and differentiation (indirect evidence suggesting this possibility in addition to SVZ activation was also presented in Magavi et al., 2000). The targeted neurons themselves, of course, will alter their gene expression. Beyond these populations, there are other populations of glia and other cells that can regulate their gene expression in the microenvironment.

\section{REFERENCES}

Alcamo, E. A., Chirivella, L., Dautzenberg, M., Dobreva, G., Farinas, I., Grosschedl, R., and Mcconnell, S. K. (2008). Satb2 regulates callosal projection neuron identity in the developing cerebral cortex. Neuron 57, 364-377.

Alvarez-Buylla, A., Garcia-Verdugo, J. M., and Tramontin, A. D. (2001). A unified hypothesis on the lineage of neural stem cells. Nat. Rev. Neurosci. 2, 287-293.

Alvarez-Buylla, A., Kohwi, M., Nguyen, T. M., and Merkle, F. T. (2008). The heterogeneity of adult neural stem cells and the emerging complexity of their niche. Cold Spring Harb. Symp. Quant. Biol. 73, 357-365.

Anthony, T. E., Klein, C., Fishell, G., and Heintz, N. (2004). Radial glia serve as neuronal progenitors in all regions of the central nervous system. Neuron 41, 881-890.

Arai, Y., Funatsu, N., NumayamaTsuruta, K., Nomura, T., Nakamura, S., and Osumi, N. (2005). Role of Fabp7, a downstream gene of Pax6, in the maintenance of neuroepithelial cells during early embryonic development of the rat cortex. $J$. Neurosci. 25, 9752-9761.

Arlotta, P., Molyneaux, B. J., Chen, J., Inoue, J., Kominami, R., and Macklis, J. D. (2005). Neuronal subtype-specific genes that control corticospinal motor neuron development in vivo. Neuron 45, 207-221.

Arvidsson, A., Collin, T., Kirik, D., Kokaia, Z., and Lindvall, O. (2002).

Future studies could elucidate function(s) and mechanism(s) of these genes, proteins, and pathways. It appears likely that fundamental mechanisms are shared during neurogenesis in the developing and adult CNS.

\section{ACKNOWLEDGMENTS}

We thank Vitek Lipski for technical assistance. We thank the National Center for Biotechnology Information's Gene Expression Omnibus (GEO; http://www.ncbi.nlm.nih.gov/sites/entrez), and the Eurexpress/Genepaint consortium (http://www.eurexpress. org/ee/intro.html) publicly available databases for generously providing free access to their important data. This work was partially supported by the National Institutes of Health (grants NS49553 and NS45523), the Harvard Stem Cell Institute, the Jane and Lee Seidman Fund for CNS Research, and the Emily and Robert Pearlstein Fund for Nervous System Repair (Jeffrey D. Macklis), with additional infrastructure support by National Institutes of Health grant NS41590 (Jeffrey D. Macklis). Paola Arlotta was partially supported by a Wills Foundation Fellowship. U. Shivraj Sohur was partially supported by a seed grant from the Harvard Stem Cell Institute.

and Gotz, M. (2009). Adult generation of glutamatergic olfactory bulb interneurons. Nat. Neurosci. 12, 1524-1533.

Britanova, O., De Juan Romero, C., Cheung, A., Kwan, K. Y., Schwark, M., Gyorgy, A., Vogel, T., Akopov, S., Mitkovski, M., Agoston, D., Sestan, N., Molnar, Z., and Tarabykin, V. (2008). Satb2 is a postmitotic determinant for upper-layer neuron specification in the neocortex. Neuron 57, 378-392.

Chambers, C. B., Peng, Y., Nguyen, H., Gaiano, N., Fishell, G., and Nye, J. S. (2001). Spatiotemporal selectivity of response to Notchl signals in mammalian forebrain precursors. Development 128 , 689-702.

Chen, B., Schaevitz, L. R., and Mcconnell, S. K. (2005). Fezl regulates the differentiation and axon targeting of layer 5 subcortical projection neurons in cerebral cortex. Proc. Natl. Acad. Sci. U.S.A. 102, 17184-17189.

Chen, J., Magavi, S. S., and Macklis, J. D. (2004). Neurogenesis of corticospinal motor neurons extending spinal projections in adult mice. Proc. Natl. Acad. Sci. U.S.A. 101, 16357-16362.

Chojnacki, A. K., Mak, G. K., and Weiss, S. (2009). Identity crisis for adult periventricular neural stem cells: subventricular zone astrocytes, ependymal cells or both? Nat. Rev. Neurosci. 10, 153-163.

Costa, M. R., Kessaris, N., Richardson, W. D., Gotz, M., and Hedin-Pereira, C. (2007). The marginal zone/layer
I as a novel niche for neurogenesis and gliogenesis in developing cerebral cortex. J. Neurosci. 27, 11376-11388.

Doetsch, F., Caille, I., Lim, D. A., Garcia-Verdugo, J. M., and AlvarezBuylla, A. (1999). Subventricular zone astrocytes are neural stem cells in the adult mammalian brain. Cell 97, 703-716.

Emsley, J. G., and Macklis, J. D. (2006). Astroglial heterogeneity closely reflects the neuronaldefined anatomy of the adult murine CNS. Neuron Glia Biol. 2 175-186.

Fame, R. M., Macdonald, J. L., and Macklis, J. D. (2011). Development, specification, and diversity of callosal projection neurons. Trends Neurosci. 34, 41-50.

Fricker-Gates, R. A., Shin, J. J., Tai, C. C., Catapano, L. A., and Macklis, J. D. (2002). Late-stage immature neocortical neurons reconstruct interhemispheric connections and form synaptic contacts with increased efficiency in adult mouse cortex undergoing targeted neurodegeneration. J. Neurosci. 22, 4045-4056.

Gal, J. S., Morozov, Y. M., Ayoub, A. E., Chatterjee, M., Rakic, P., and Haydar T. F. (2006). Molecular and morphological heterogeneity of neural precursors in the mouse neocortical proliferative zones. J. Neurosci. 26, 1045-1056.

Gentleman, R. (2005). Reproducible research: a bioinformatics case study. Stat. Appl. Genet. Mol. Biol. 4, Article 2 . 
Gotz, M., Hartfuss, E., and Malatesta, P. (2002). Radial glial cells as neuronal precursors: a new perspective on the correlation of morphology and lineage restriction in the developing cerebral cortex of mice. Brain Res. Bull. 57, 777-788.

Hack, M. A., Saghatelyan, A., De Chevigny, A., Pfeifer, A., Ashery-Padan, R., Lledo, P. M., and Gotz, M. (2005). Neuronal fate determinants of adult olfactory bulb neurogenesis. Nat. Neurosci. 8, 865-872.

Han, W., Kwan, K. Y., Shim, S., Lam, M. M., Shin, Y., Xu, X., Zhu, Y., Li, M., and Sestan, N. (2011). TBR1 directly represses Fezf2 to control the laminar origin and development of the corticospinal tract. Proc. Natl. Acad. Sci. U.S.A. 108, 3041-3046.

Hartfuss, E., Galli, R., Heins, N., and Gotz, M. (2001). Characterization of CNS precursor subtypes and radial glia. Dev. Biol. 229, 15-30.

Hernit-Grant, C. S., and Macklis, J. D. (1996). Embryonic neurons transplanted to regions of targeted photolytic cell death in adult mouse somatosensory cortex re-form specific callosal projections. Exp. Neurol. 139, 131-142.

Hirsch-Reinshagen, V., Zhou, S., Burgess, B. L., Bernier, L., Mcisaac, S. A., Chan, J. Y., Tansley, G. H., Cohn, J. S., Hayden, M. R., and Wellington, C. L. (2004). Deficiency of ABCA1 impairs apolipoprotein $\mathrm{E}$ metabolism in brain. J. Biol. Chem. 279, 41197-41207.

Irizarry, R. A., Hobbs, B., Collin, F., Beazer-Barclay, Y. D., Antonellis, K. J., Scherf, U., and Speed, T. P. (2003). Exploration, normalization, and summaries of high density oligonucleotide array probe level data. Biostatistics 4, 249-264.

Ishida, N. (2007). Circadian clock, cancer and lipid metabolism. Neurosci. Res. 57, 483-490.

Joshi, P. S., Molyneaux, B. J., Feng, L., Xie, X., Macklis, J. D., and Gan, L. (2008). Bhlhb5 regulates the postmitotic acquisition of area identities in layers II-V of the developing neocortex. Neuron 60, 258-272.

Karasinska, J. M., Rinninger, F., Lutjohann, D., Ruddle, P., Franciosi, S., Kruit, J. K., Singaraja, R. R., HirschReinshagen, V., Fan, J., Brunham, L. R., Bissada, N., Ramakrishnan, R., Wellington, C. L., Parks, J. S., and Hayden, M. R. (2009). Specific loss of brain ABCA1 increases brain cholesterol uptake and influences neuronal structure and function. J. Neurosci. 29, 3579-3589.

Kempermann, G. (2011). Seven principles in the regulation of adult neurogenesis. Eur. J. Neurosci. 33, 1018-1024.

Kim, W. S., Weickert, C. S., and Garner, B. (2008). Role of ATP-binding cassette transporters in brain lipid transport and neurological disease. J. Neurochem. 104, 1145-1166.

Kohwi, M., Osumi, N., Rubenstein, J. L., and Alvarez-Buylla, A. (2005). Pax6 is required for making specific subpopulations of granule and periglomerular neurons in the olfactory bulb. J. Neurosci. 25, 6997-7003.

Lai, T., Jabaudon, D., Molyneaux, B. J., Azim, E., Arlotta, P., Menezes, J. R., and Macklis, J. D. (2008). SOX5 controls the sequential generation of distinct corticofugal neuron subtypes. Neuron 57, 232-247.

Leavitt, B. R., Hernit-Grant, C. S., and Macklis, J. D. (1999). Mature astrocytes transform into transitional radial glia within adult mouse neocortex that supports directed migration of transplanted immature neurons. Exp. Neurol. 157, 43-57.

Leone, D. P., Srinivasan, K., Chen, B., Alcamo, E., and Mcconnell, S. K. (2008). The determination of projection neuron identity in the developing cerebral cortex. Curr. Opin. Neurobiol. 18, 28-35.

Lledo, P. M., Merkle, F. T., and AlvarezBuylla, A. (2008). Origin and function of olfactory bulb interneuron diversity. Trends Neurosci. 31, 392-400.

Ma, D. K., Marchetto, M. C., Guo, J. U., Ming, G. L., Gage, F. H., and Song, H. (2010). Epigenetic choreographers of neurogenesis in the adult mammalian brain. Nat. Neurosci. 13, 1338-1344.

MacDonald, J. L., Fame, R. M., Azim, E., Shnider, S. J., Molyneaux, B. J., Arlotta, P., and Macklis, J. D. (2012). "Specification of cortical projection neurons: transcriptional mechanisms," in Developmental Neuroscience: A Comprehensive Reference, eds P. Rakic and J. L. Rubenstein (Oxford: Elsevier).

Macklis, J. D. (1993). Transplanted neocortical neurons migrate selectively into regions of neuronal degeneration produced by chromophoretargeted laser photolysis. J. Neurosci. 13, 3848-3863.

Magavi, S. S., Leavitt, B. R., and Macklis, J. D. (2000). Induction of neurogenesis in the neocortex of adult mice. Nature 405, 951-955.

Magavi, S. S., Mitchell, B. D., Szentirmai, O., Carter, B. S., and Macklis, J. D. (2005). Adult-born and preexisting olfactory granule neurons undergo distinct experience-dependent modifications of their olfactory responses in vivo. J. Neurosci. 25, 10729-10739. Mariani, E., Seripa, D., Ingegni, T. Nocentini, G., Mangialasche, F., Ercolani, S., Cherubini, A., Metastasio, A., Pilotto, A., Senin, U., and Mecocci, P. (2006). Interaction of CTSD and A2M polymorphisms in the risk for Alzheimer's disease. $J$. Neurol. Sci. 247, 187-191.

Masliah, E., Mallory, M., Ge, N., Alford, M., Veinbergs, I., and Roses, A. D. (1995). Neurodegeneration in the central nervous system of apoEdeficient mice. Exp. Neurol. 136, 107-122.

McKenna, W. L., Betancourt, J., Larkin, K. A., Abrams, B., Guo, C., Rubenstein, J. L., and Chen, B. (2011). Tbr1 and Fezf2 regulate alternate corticofugal neuronal identities during neocortical development. J. Neurosci. 31, 549-564.

McTavish, N., Copeland, L. A., Saville, M. K., Perkins, N. D., and Spruce, B. A. (2007). Proenkephalin assists stress-activated apoptosis through transcriptional repression of NFkappaB- and p53-regulated gene targets. Cell Death Differ. 14 1700-1710.

Merkle, F. T., Mirzadeh, Z., and AlvarezBuylla, A. (2007). Mosaic organization of neural stem cells in the adult brain. Science 317, 381-384.

Mizutani, K., Yoon, K., Dang, L., Tokunaga, A., and Gaiano, N. (2007). Differential Notch signalling distinguishes neural stem cells from intermediate progenitors. Nature 449 , 351-355.

Molyneaux, B. J., Arlotta, P., Hirata, T., Hibi, M., and Macklis, J. D. (2005). Fezl is required for the birth and specification of corticospinal motor neurons. Neuron 47, 817-831.

Molyneaux, B. J., Arlotta, P., Menezes, J. R., and Macklis, J. D. (2007). Neuronal subtype specification in the cerebral cortex. Nat. Rev. Neurosci. 8, 427-437.

Moriwaki, Y., Begum, N. A., Kobayashi, M., Matsumoto, M., Toyoshima, K. and Seya, T. (2001). Mycobacterium bovis bacillus Calmette-Guerin and its cell wall complex induce a novel lysosomal membrane protein, SIMPLE, that bridges the missing link between lipopolysaccharide and p53-inducible gene, LITAF(PIG7), and estrogen-inducible gene, EET-1. J. Biol. Chem. 276, 23065-23076.

Myokai, F., Takashiba, S., Lebo, R., and Amar, S. (1999). A novel lipopolysaccharide-induced transcription factor regulating tumor necrosis factor alpha gene expression: molecular cloning, sequencing, characterization, and chromosomal assignment. Proc. Natl. Acad. Sci. U.S.A. 96, 4518-4523.

Nakatomi, H., Kuriu, T., Okabe, S., Yamamoto, S., Hatano, O., Kawahara, N., Tamura, A., Kirino, T., and Nakafuku, M. (2002). Regeneration of hippocampal pyramidal neurons after ischemic brain injury by recruitment of endogenous neural progenitors. Cell 110, 429-441.

Nataf, S., Anginot, A., Vuaillat, C., Malaval, L., Fodil, N., Chereul, E., Langlois, J. B., Dumontel, C., Cavillon, G., Confavreux, C., Mazzorana, M., Vico, L., Belin, M. F., Vivier, E., Tomasello, E., and Jurdic, P. (2005). Brain and bone damage in KARAP/DAP12 loss-of-function mice correlate with alterations in microglia and osteoclast lineages. Am. J. Pathol. 166, 275-286.

Noctor, S. C., Flint, A. C., Weissman, T. A., Dammerman, R. S., and Kriegstein, A. R. (2001). Neurons derived from radial glial cells establish radial units in neocortex. Nature 409, 714-720.

Ozdinler, P. H., and Macklis, J. D. (2006). IGF-I specifically enhances axon outgrowth of corticospinal motor neurons. Nat. Neurosci. 9, 1371-1381.

Parent, J. M., Vexler, Z. S., Gong, C., Derugin, N., and Ferriero, D. M (2002). Rat forebrain neurogenesis and striatal neuron replacement after focal stroke. Ann. Neurol. 52, 802-813.

Partanen, S., Haapanen, A., Kielar, C., Pontikis, C., Alexander, N., Inkinen T., Saftig, P., Gillingwater, T. H., Cooper, J. D., and Tyynela, J. (2008). Synaptic changes in the thalamocortical system of cathepsin D-deficient mice: a model of human congenital neuronal ceroid-lipofuscinosis. J. Neuropathol. Exp. Neurol. 67, 16-29.

Pinto, L., Mader, M. T., Irmler, M. Gentilini, M., Santoni, F., Drechsel, D., Blum, R., Stahl, R., Bulfone, A., Malatesta, P., Beckers, J., and Gotz, M. (2008). Prospective isolation of functionally distinct radial glial subtypes - lineage and transcriptome analysis. Mol. Cell. Neurosci. 38, 15-42.

Polyak, K., Xia, Y., Zweier, J. L., Kinzler, K. W., and Vogelstein, B. (1997) A model for p53-induced apoptosis. Nature 389, 300-305.

Roumier, A., Bechade, C., Poncer, J. C., Smalla, K. H., Tomasello, E., Vivier, E., Gundelfinger, E. D., Triller, A., and Bessis, A. (2004). Impaired synaptic function in the microglial KARAP/DAP12-deficient mouse. $J$. Neurosci. 24, 11421-11428. 
Rousselot, P., Heintz, N., and Nottebohm, F. (1997). Expression of brain lipid binding protein in the brain of the adult canary and its implications for adult neurogenesis. J. Comp. Neurol. 385, 415-426.

Sanosaka, T., Namihira, M., Asano, H., Kohyama, J., Aisaki, K., Igarashi, K., Kanno, J., and Nakashima, K. (2008). Identification of genes that restrict astrocyte differentiation of midgestational neural precursor cells. $\mathrm{Neu}$ roscience $155,780-788$

Scharff, C., Kirn, J. R., Grossman, M., Macklis, J. D., and Nottebohm, F. (2000). Targeted neuronal death affects neuronal replacement and vocal behavior in adult songbirds. Neuron 25, 481-492.

Schauwecker, P. E. (2006). Genetic influence on neurogenesis in the dentate gyrus of two strains of adult mice. Brain Res. 1120, 83-92.

Seri, B., Garcia-Verdugo, J. M., Mcewen, B. S., and Alvarez-Buylla, A. (2001). Astrocytes give rise to new neurons in the adult mammalian hippocampus. J. Neurosci. 21, 7153-7160.

Shapiro, L. A., Korn, M. J., Shan, Z., and Ribak, C. E. (2005). GFAPexpressing radial glia-like cell bodies are involved in a one-toone relationship with doublecortinimmunolabeled newborn neurons in the adult dentate gyrus. Brain Res. 1040, 81-91.

Sheen, V. L., and Macklis, J. D. (1995). Targeted neocortical cell death in adult mice guides migration and differentiation of transplanted embryonic neurons. J. Neurosci. 15, 8378-8392.

Shoemaker, L. D., and Arlotta, P. (2010). Untangling the cortex: advances in understanding specification and differentiation of corticospinal motor neurons. Bioessays 32, 197-206.

Smyth, G. K. (2004). Linear models and empirical Bayes methods for assessing differential expression in microarray experiments. Stat. Appl. Genet. Mol. Biol. 3, Article 3.

Sohur, U. S., Emsley, J. G., Mitchell, B. D., and Macklis, J. D. (2006). Adult neurogenesis and cellular brain repair with neural progenitors, precursors and stem cells. Philos. Trans. R. Soc. Lond. B Biol. Sci. 361, 1477-1497.

Sousa, A. D., Berg, J. S., Robertson, B. W., Meeker, R. B., and Cheney, R. E. (2006). Myol0 in brain: developmental regulation, identification of a headless isoform and dynamics in neurons. J. Cell. Sci. 119, 184-194.

Steele, A. D., Emsley, J. G., Ozdinler, P. H., Lindquist, S., and Macklis, J. D. (2006). Prion protein (PrPc) positively regulates neural precursor proliferation during developmental and adult mammalian neurogenesis. Proc. Natl. Acad. Sci. U.S.A. 103, 3416-3421.

Stevens, B., Allen, N. J., Vazquez, L. E., Howell, G. R., Christopherson, K. S., Nouri, N., Micheva, K. D., Mehalow, A. K., Huberman, A. D., Stafford, B. Sher, A., Litke, A. M., Lambris, J. D., Smith, S. J., John, S. W., and Barres, B. A. (2007). The classical complement cascade mediates CNS synapse elimination. Cell 131, 1164-1178.

Street, V. A., Bennett, C. L., Goldy, J. D., Shirk, A. J., Kleopa, K. A., Tempel, B. L., Lipe, H. P., Scherer, S. S., Bird, T. D., and Chance, P. F. (2003). Mutation of a putative protein degradation gene LITAF/SIMPLE in Charcot-Marie-Tooth disease 1C. Neurology 60, 22-26.

Suh, H., Deng, W., and Gage, F. H. (2009). Signaling in adult neurogenesis. Annu. Rev. Cell Dev. Biol. 25, 253-275.

Tomassy, G. S., De Leonibus, E., Jabaudon, D., Lodato, S., Alfano, C., Mele, A., Macklis, J. D., and Studer, M. (2010). Area-specific temporal control of corticospinal motor neuron differentiation by COUP-TFI. Proc. Natl. Acad. Sci. U.S.A. 107, 3576-3581.

Tusher, V. G., Tibshirani, R., and Chu, G. (2001). Significance analysis of microarrays applied to the ionizing radiation response. Proc. Natl. Acad. Sci. U.S.A. 98, 5116-5121.

Verma, R., Chauhan, C., Saleem, Q., Gandhi, C., Jain, S., and Brahmachari, S. K. (2004). A nonsense mutation in the synaptogyrin 1 gene in a family with schizophrenia. Biol. Psychiatry 55, 196-199.

Visel, A., Thaller, C., and Eichele, G. (2004). GenePaint.org: an atlas of gene expression patterns in the mouse embryo. Nucleic Acids Res. 32 D552-D556.

Wahrle, S. E., Jiang, H., Parsadanian, M., Legleiter, J., Han, X., Fryer, J. D., Kowalewski, T., and Holtzman, D. M. (2004). ABCA1 is required for normal central nervous system ApoE levels and for lipidation of astrocytesecreted apoE. J. Biol. Chem. 279, 40987-40993.

Wang, Y., Sheen, V. L., and Macklis, J. D. (1998). Cortical interneurons upregulate neurotrophins in vivo in response to targeted apoptotic degeneration of neighboring pyramidal neurons. Exp. Neurol. 154, 389-402.

Wu, S. X., Goebbels, S., Nakamura, K. Kometani, K., Minato, N., Kaneko, T., Nave, K. A., and Tamamaki, N. (2005). Pyramidal neurons of upper cortical layers generated by NEX positive progenitor cells in the subventricular zone. Proc. Natl. Acad. Sci. U.S.A. 102, 17172-17177.

Zimmerman, A. W., and Veerkamp, J. H. (2002). New insights into the structure and function of fatty acidbinding proteins. Cell. Mol. Life Sci. 59, 1096-1116.

Conflict of Interest Statement: The authors declare that the research was conducted in the absence of any commercial or financial relationships that could be construed as a potential conflict of interest.

Received: 04 August 2011; accepted: 18 January 2012; published online: 06 February 2012.

Citation: Sohur US, Arlotta P and Macklis JD (2012) Developmental controls are re-expressed during induction of neurogenesis in the neocortex of young adult mice. Front. Neurosci. 6:12. doi: 10.3389/fnins.2012.00012

This article was submitted to Frontiers in Neurogenesis, a specialty of Frontiers in Neuroscience.

Copyright (c) 2012 Sohur, Arlotta and Macklis. This is an open-access article distributed under the terms of the Creative Commons Attribution Non Commercial License, which permits noncommercial use, distribution, and reproduction in other forums, provided the original authors and source are credited. 


\section{APPENDIX}

Table A1 | Genes differentially expressed in regions of induced young adult neurogenesis.

\begin{tabular}{|c|c|c|c|c|c|}
\hline Full name & Gene symbol & Fold change & $P$-value & Affymetrix ID & Accession number \\
\hline Apolipoprotein E & Apoe & 1.20 & 4.00E-04 & 95356_at & D00466 \\
\hline Basigin & Bsg & 1.17 & 1.90E-03 & 101078_at & Y16258 \\
\hline Calcium/calmodulin-dependent protein kinase II alpha & Camk2a & 7.21 & $4.71 \mathrm{E}-03$ & 93659_at & X14836 \\
\hline Calcium/calmodulin-dependent protein kinase II, delta & Camk2d & 2.18 & $9.50 \mathrm{E}-03$ & 93214_at & AF059029 \\
\hline CD63 molecule & Cd63 & 1.27 & $2.00 \mathrm{E}-05$ & 160493_at & D16432 \\
\hline Carbohydrate sulfotransferase 2 & Chst2 & 2.07 & $8.08 \mathrm{E}-03$ & 97110_at & AW121776 \\
\hline Coatomer protein complex, subunit beta 1 & Copb1 & -1.36 & $8.40 \mathrm{E}-04$ & 94992_at & Al840667 \\
\hline Cellular retinoic acid binding protein $\|$ & Crabp2 & -2.27 & $2.14 \mathrm{E}-03$ & 100127_at & M35523 \\
\hline Cryptochrome 2 (photolyase-like) & Cry2 & 2.24 & $3.27 \mathrm{E}-03$ & 97724_at & AB003433 \\
\hline Casein kinase 1 , delta & Csnk1d & 1.84 & $9.48 \mathrm{E}-03$ & 97263_s_at & Al846289 \\
\hline Epidermal growth factor receptor pathway substrate 15 & Eps15 & 1.98 & 3.55E-03 & 104006_at & L21768 \\
\hline FBJ osteosarcoma oncogene & Fos & -1.79 & $6.13 \mathrm{E}-03$ & 160901_at & V00727 \\
\hline Ferritin light chain 1 & Ft/1 & 1.42 & 1.53E-03 & 99872_s_at & L39879 \\
\hline Glutathione S-transferase, mu 1 & Gstm1 & -1.35 & $5.34 \mathrm{E}-03$ & 93543_f_at & J03952 \\
\hline General transcription factor II H, polypeptide 1 & Gtf2h1 & 1.17 & 1.04E-03 & 94811_s_at & AJ002366 \\
\hline Histocompatibility 2, D region & H2-d1 & 1.75 & $3.80 \mathrm{E}-04$ & 101886_f_at & X52490 \\
\hline MHC class I like protein GS10 & $H 2-g s 10$ & 1.69 & 7.04E-03 & 98438_f_at & X16202 \\
\hline Histocompatibility $2, \mathrm{~K} 1, \mathrm{~K}$ region & $H 2-k 1$ & 3.82 & $5.15 \mathrm{E}-03$ & 93120_f_at & V00746 \\
\hline Histocompatibility 2, Q region locus 2 & $H 2-q 2$ & 1.82 & $2.00 \mathrm{E}-04$ & 102161_f_at & X58609 \\
\hline Histocompatibility 2, T region locus 23 & $\mathrm{H} 2-\mathrm{t} 23$ & 1.44 & 1.73E-03 & 98472_at & Y00629 \\
\hline HOP homeobox & Hopx & 1.37 & $5.46 \mathrm{E}-03$ & 96672_at & AW123564 \\
\hline Peroxiredoxin 6 & $\operatorname{Prd} 66$ & 1.49 & 1.11E-03 & 100332_s_at & AF093853 \\
\hline RAB11a, member RAS oncogene family & Rab11a & 1.14 & 4.99E-03 & 92854_at & D50500 \\
\hline RAN GTPase activating protein 1 & Rangap1 & 1.67 & $5.74 \mathrm{E}-03$ & 98603_s_at & U20857 \\
\hline ribosomal protein, large, P1 & Rplp1 & -1.48 & 1.39E-03 & 161480_i_at & AV055186 \\
\hline Ribosomal protein S27 & Rps27 & -1.13 & $6.40 \mathrm{E}-03$ & 96300_f_at & Al854238 \\
\hline Ras-related GTP binding D & Rragd & 1.85 & 8.99E-03 & 93614_at & AA600647 \\
\hline S100 calcium binding protein $A 6$ & S100a6 & 1.27 & $8.40 \mathrm{E}-04$ & 92770_at & X66449 \\
\hline Serine incorporator 3 & Serinc3 & 1.15 & $6.79 \mathrm{E}-03$ & 100151_at & L29441 \\
\hline $\begin{array}{l}\text { Sirtuin } 2 \text { (silent mating type information regulation } 2 \text {, } \\
\text { homolog) } 2 \text { (S. cerevisiae) }\end{array}$ & Sirt2 & 1.34 & 7.29E-03 & 95502_at & Al840267 \\
\hline Small nucleolar RNA host gene 11 & Snhg11 & -1.93 & 7.29E-03 & 97752_at & Al854265 \\
\hline Synaptogyrin 1 & Syngr1 & 2.71 & $3.30 \mathrm{E}-04$ & 102221_at & AJ002306 \\
\hline Synaptotagmin I & Syt1 & 2.62 & $5.94 \mathrm{E}-03$ & 93005_at & D37792 \\
\hline
\end{tabular}


Table A1 | Continued

\begin{tabular}{|c|c|c|c|c|c|}
\hline Full name & Gene symbol & Fold change & $P$-value & Affymetrix ID & Accession number \\
\hline Thrombospondin 1 & Thbs1 & -2.21 & $5.79 \mathrm{E}-03$ & 160469_at & M62470 \\
\hline Trafficking protein, kinesin binding 2 & Trak2 & 2.01 & 1.64E-03 & 97111_at & AA290180 \\
\hline Tubulin, beta 2 & Tubb2a & 1.19 & 4.09E-03 & 94835_f_at & M28739 \\
\hline Tubulin, beta 5 & Tubb5 & 1.13 & 7.32E-03 & 94788_f_at & X04663 \\
\hline Zinc finger, X-linked, duplicated A & $Z x d a$ & -2.16 & 7.66E-03 & 104191_at & Al322972 \\
\hline \multicolumn{6}{|l|}{ B } \\
\hline Alpha-2-macroglobulin & $A 2 m$ & 2.22 & 0.01 & 104486_at & Al850558 \\
\hline ADAM metallopeptidase domain 10 & Adam 10 & 1.86 & 0.01 & 100751_at & AF011379 \\
\hline Adipose differentiation-related protein & Adfp & 1.53 & 0.02 & 98589_at & M93275 \\
\hline Caspase 9, apoptosis-related cysteine peptidase & Casp9 & 2.29 & 0.02 & 100368_at & AB019601 \\
\hline CD68 molecule & Cd68 & 2.49 & 0.02 & 103016_s_at & X68273 \\
\hline Colony stimulating factor 1 receptor & Csf1r & 1.79 & 0.04 & 104354_at & X06368 \\
\hline CUG triplet repeat, RNA binding protein 1 & Cugbp1 & 2.67 & 0.05 & 93630_at & X61451 \\
\hline Ecotropic viral integration site $2 \mathrm{~A}$ & Evi2a & 2 & 0.01 & 98026_g_at & M34896 \\
\hline $\mathrm{H} 2-\mathrm{K} 2$ histocompatibility $2, \mathrm{~K}$ region locus 2 & $H 2-k 2$ & 1.74 & 0.01 & 93714_f_at & Al117211 \\
\hline Histocompatibility 2, Q region locus 7 & $H 2-q 7$ & 1.72 & 0.04 & 98438_f_at & X16202 \\
\hline Major histocompatibility complex, class I, C & Hla-c & 1.9 & 0.00 & 101886_f_at & X52490 \\
\hline 3-Hydroxy-3-methylglutaryl-coenzyme A reductase & $\mathrm{Hmgcr}$ & 1.63 & 0.02 & 99425_at & X07888 \\
\hline Lipopolysaccharide-induced TNF factor & Litaf & 1.57 & 0.01 & 93753_at & Al852632 \\
\hline Mitogen-activated protein kinase kinase kinase 7 & Map3k7 & 1.55 & 0.04 & 160854_at & D76446 \\
\hline TAP binding protein (tapasin) & Tapbp & 1.55 & 0.01 & 100154_at & Al836367 \\
\hline Trans-Golgi network protein; trans-Golgi network protein 2 & Tgoln 1; Tgoln2 & 1.68 & 0.04 & 93881_i_at & D50032 \\
\hline
\end{tabular}




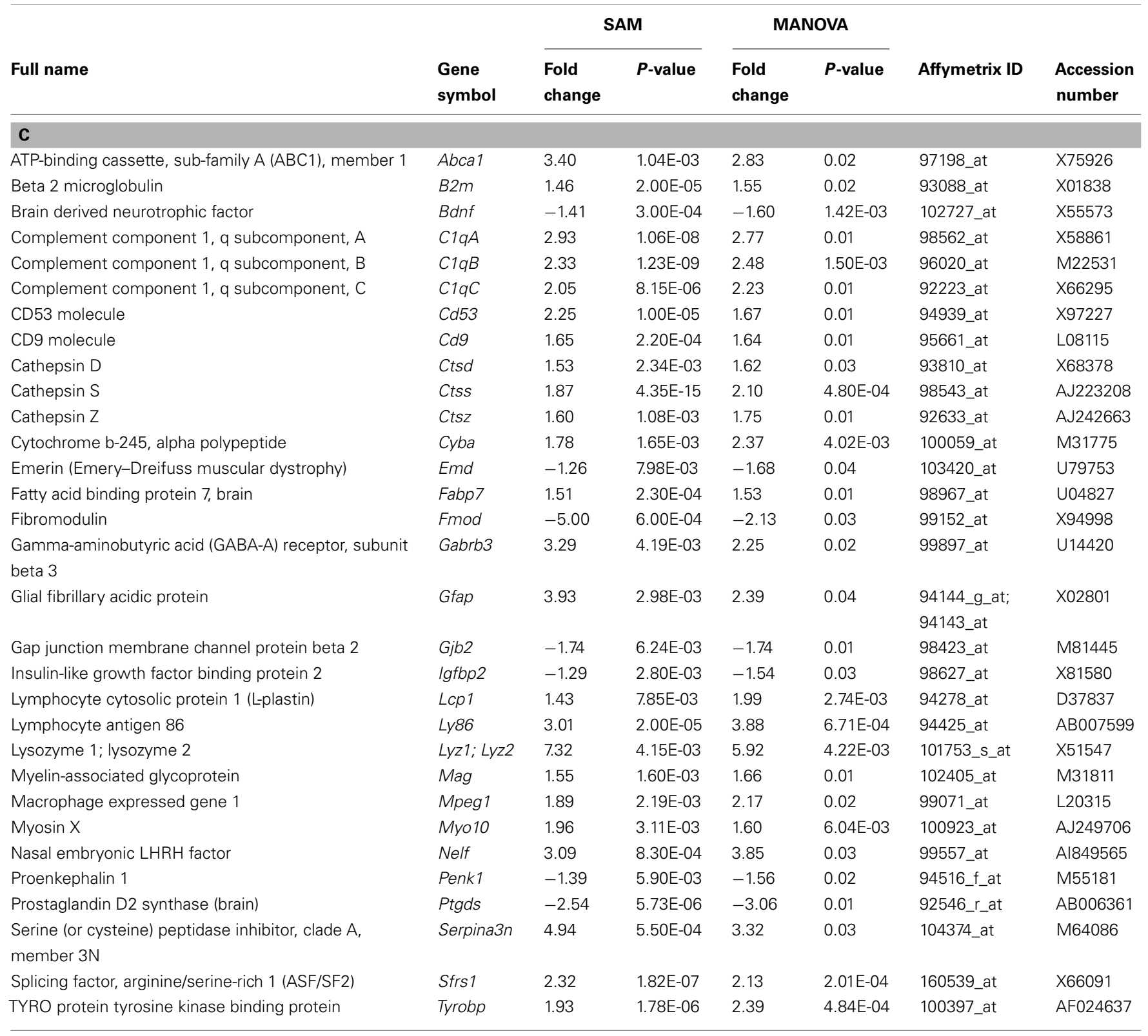

(A) Genes identified by statistical analysis of microarrays (SAM), but not by multivariate analysis of variance (also known as linear modeling; MANOVA). (B) Genes identified by MANOVA, but not by SAM. (C) Genes identified by both SAM and MANOVA (Source: .CEL files from this work will be deposited at NCBI's GEO). 